\title{
The improvement of bolted joints model via finite element model updating method
}

\author{
M.A Yunus, ${ }^{12}$, M.N Abdul Rani12, M.A.S. Aziz Shah¹, M.S M. Sani³ and Z.Yahya ${ }^{4}$ \\ ${ }^{1}$ Structural Dynamics Analysis \& Validation (SDAV), Faculty of Mechanical Engineering, Universiti Teknologi MARA (UiTM), 40450 Shah Alam, \\ Selangor, Malaysia \\ Phone: +60355436020; Fax: +60355436073 \\ 2 Institute for Infrastructure Engineering and Sustainable Management (IIESM), Universiti Teknologi MARA (UiTM), 40450 Shah Alam, \\ Selangor, Malaysia \\ ${ }^{3}$ Faculty of Mechanical and Automotive Engineering, Universiti Malaysia Pahang, 26600 Pekan, Pahang, Malaysia \\ ${ }^{4}$ Faculty of Computing and Multimedia, Kolej Universiti Poly-Tech MARA, 56100, Kuala Lumpur
}

\begin{abstract}
Efficient schemes to represent mathematical model of thin-sheet metal structures jointed by bolted joints for accurately predict the structure dynamic behaviour has been a significant unresolved issue in structural dynamics community. The biggest challenge is to efficiently incorporate the joints local deformation effects on the developed mathematical model via finite element (FE) method. Generally, the joints local deformation typically exerts on the joints mating area. To solve this issue, this paper proposes efficient schemes to represent mathematical model of thin-sheet metal structures jointed by bolted joints with application to accurately calculate the structure dynamic behaviour using FE model updating method. The initial FE model of the assembled structure was developed by employed Fastener Connector (CFAST) in MSC NASTRAN software to represent the bolted joints while, the inclusion of the local deformation effects at the bolted joints mating area was represented by contact elements. Then, the responses obtained from the FE model was evaluated by weight up with experimental data. FE model updating (FEMU) method then was utilised for minimising prediction discrepancies originated from the initial FE model based on the experimental data. The proposed scheme shows the accuracy of the initial prediction was improved from $25.03 \%$ to $14.65 \%$ while the accuracy of the predicted mode shapes via modal assurance criterion (MAC) analysis were above 0.8 . Therefore, the findings offer useful schemes for improving the quality of predicted dynamic behaviour, particularly in the thinsheet metal jointed structure and the developed model can be used with confident for any subsequence dynamic analyses.
\end{abstract}

ARTICLE HISTORY

Received: $15^{\text {th }}$ Feb. 2021

Revised: 23' Nov. 2021

Accepted: 03 $3^{\text {rd }}$ Dec. 2021

\section{KEYWORDS}

Thin sheet metal;

bolted joints;

modal based updating;

local effects

\section{INTRODUCTION}

Bolted joints have been widely used as jointed mechanism for assembled automotive structures. Typically, thin metal sheets which are in dissimilar sizes are used to form automotive structure parts which are combined together by a thousand numbers of bolted joints. The bolted joints have been preferable among others joining methods mainly because of the joint versatility such as can be easily dissembled and maintained in comparison with spot welds or adhesive [1,2]. Although the recent survey articles [3-5] reported many advances in their finding. However, the problem is that improving the predicted model of the bolted joints remains to be difficult and challenging.

Understandably, numerical analysis such as finite element (FE) method is a practical computational tool that are widely used to provide initial solutions to the engineering problems and are becoming increasingly popular in engineering design and analysis to predict the initial dynamic characteristic of structure [6]. However, the predicted result from initial FE model of the bolted joined structure is often found to be inconsistent with the experimental data. This is due to the input data of the initial FE model are made based on nominal value [7-10]. On top of that, the factors of over simplification on the jointed properties such as local geometry features, boundary conditions and inaccurate of joints modelling also affects the quality of the developed FE model.

The simplifications of the local effects can lead inaccuracy being introduced in the mathematical model of a structure [11-13]. On top of that, [14-16] mentioned that the local effects due to joints are difficult to measure and calculate theoretically and therefore the finite element models are prone to be inaccurate or incorrect. In developing mathematical model of bolted joint structure using FE method, several schemes have been implemented among the researchers and among the schemes, FE model based on solid element, coupling techniques, rigid element, and beam connectors has been frequently discussed [17]. In recent, simplified version of bolted joint in FE model such as implementation of spring elements have been demanding subject due to its versatility to represent bolt flexibility stiffness in various degree of freedoms [18]. Studies by Brown et al. [19], Xiao et al. [20] and Soderberg [21] explained the important of stiffness flexibilities in bolted joint. Omar et al. [22] discussed the implementation of swift's formulation in bush element (CBUSH) for simulating bolted joints stiffness where the finding highlights advantages of the scheme in calculating 
structure dynamic behaviour. In additions, Zhan et al. [23] analyse stochastic dynamic behaviour of bolted joint by composing bolt shank stiffness and contact stiffness in CFAST element using Hugh flexibility stiffness.

It is very crucial for engineers to develop accurate FE model for improving structure's behaviour at the design level apart of savings in terms of money and time prior to be used for subsequence analysis [4, 24]. Furthermore, accuracy of FE model can be evaluated by means of model validation, which refers to the process of determining the degree of accurateness of the initial model based on the modal properties of the joints that can be extracted from the experimental counterpart. Subsequently, the responses of the initial FE model particularly natural frequencies and mode shapes are required to be match up against the experimental counterpart to verify the validity the developed FE model.

This paper proposes efficient scheme to represent mathematical model of bolted joint in assembled thin-sheet metal structure for accurately predict the structure dynamic behaviour. Initially, the mathematical model of the thin-sheet metal components of the assembled structure namely as Thin-Plate 1 and Thin-Plate 2 are develop using FE method and the predicted dynamic behaviour of Thin-Plate 1 and Thin-Plate 2 are calculated in term of natural frequencies and mode shapes. For focusing on modelling of the bolted joints, the initial FE model are updated against EMA data of the plate components respectively. Then, FE model of assembled thin-sheet metal is develop by utilising the updated FE models of the plate components and CFAST element connector as bolted joints. The dynamic behaviour of the initial assembled FE model is calculated in term of natural frequencies and mode shapes. The prediction results from the initial FE model are compared with those obtained from the experimental counterpart to evaluate the model accuracy. Finally, FEMU is employed to improve the initial prediction.

\section{EXPERIMENTAL WORK}

Experimental modal analysis (EMA) is an experimental process that typically used to identify structure dynamic responses. In EMA, the identified dynamic behaviour in terms of natural frequencies, mode shapes and damping are derived from modal model of structural system [25-27]. Generally, the dynamic behaviour obtained from the experimental process are used as reference data when evaluating quality of mathematical model. In this paper, the structure under investigation which are the Thin-Plate 1, Thin-Plate 2 and the assembled structures were test using EMA procedure for obtaining structure's responses. The assembled structure was formed from Thin Plate 1 (green), Thin Plate 2 (blue) and they are assembled together by a number of bolts and nuts. The schematic of the assembled structure is shown in Figure 1. Meanwhile, the details properties of the assembled structure are tabulated in Table 1.

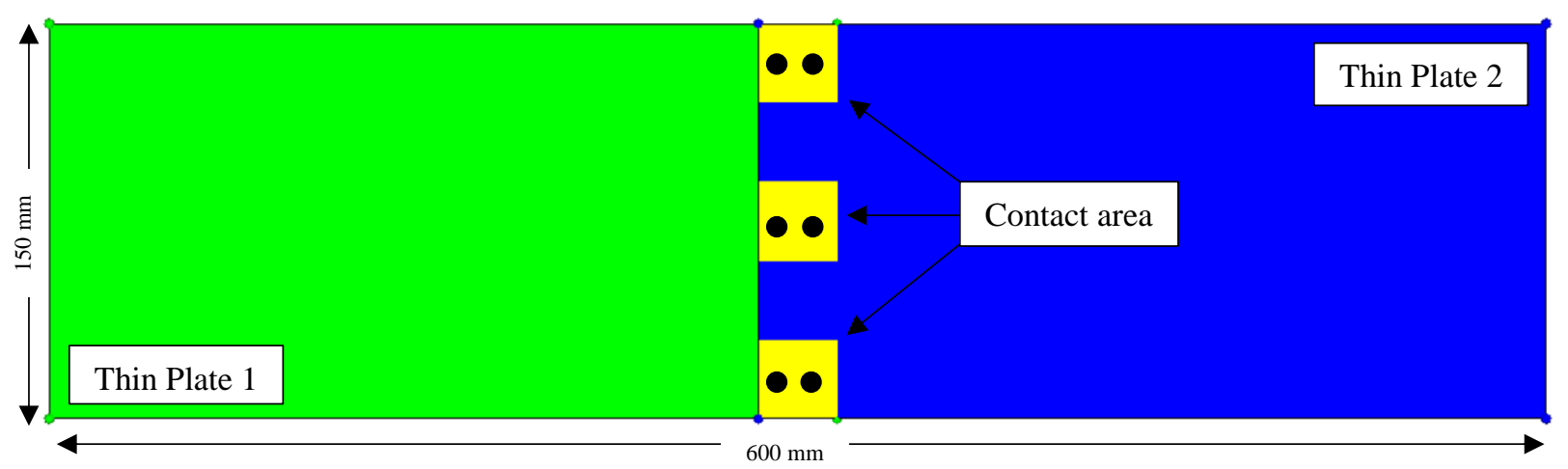

Figure 1. The schematic of the assembed Thin Plate 1-2 structures

Table 1. Mechanical properties of the Thin-Plate structures [28]

\begin{tabular}{lc}
\hline Mechanical Properties & Steel (A283) \\
\hline Young's modulus & $210 \mathrm{GPa}$ \\
Shear modulus & $81 \mathrm{GPa}$ \\
Density & $7900 \mathrm{~kg} / \mathrm{m}^{3}$ \\
Poisson's ratio & 0.31 \\
Thickness & $1.5 \mathrm{~mm}$ \\
\hline
\end{tabular}

\section{Experimental Procedure}

In the experimental work, the soft springs were employed to hang the structures to replicate free-free boundary conditions. As shown in Figure 2, LMS SCADAS was used to extract structure responses from the experimental work. Prior that, the roving accelerometer method was utilised in the experimental work for eliminating mass loading issues during the experimental work. There are two uniaxial accelerometers were employed in this work as illustrate in Figure 
2. The identified experimental data of the Thin-Plate 1, Thin-Plate 2 and the assembled structures are illustrated in Column I of Table 3, Table 4 and Table 5.

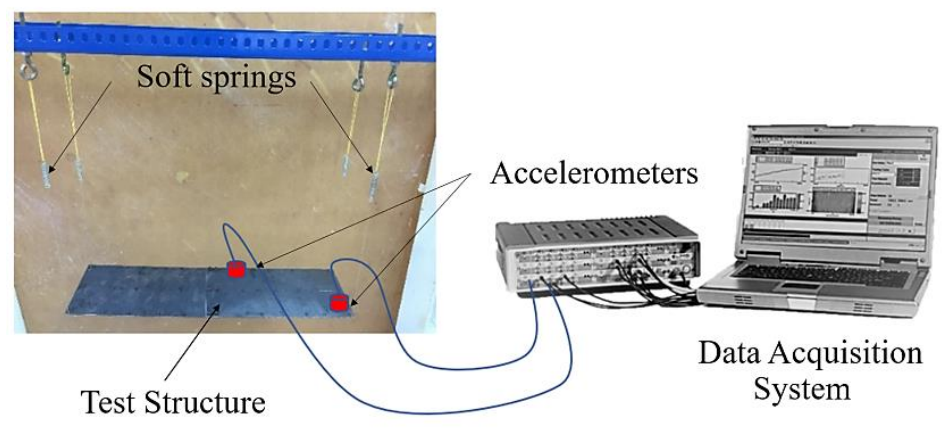

Figure 2. EMA set-up

In the EMA, the degree of freedom is a measurement point and the direction of the accelerometer defined on a test structure. The structures responses obtained in this study are based on the formulation in Eq. (1) where $H(\omega)$ represents the structural response to a unit force at the corresponding degrees of freedom and an index $\mathrm{i}$ is used to indicate a response DOF, and $\mathrm{j}$ an excitation DOF [29].

$$
\mathbf{H}_{i j}=\frac{\mathbf{X}_{i}(\omega)}{\mathbf{F}_{j}(\omega)}
$$

\section{FE MODELLING AND MODEL UPDATING}

\section{Normal Mode Analysis}

In this paper, FE model of plate components and bolted joint structures were developed by using MSC NASTRAN/PATRAN using CQUAD4 elements. CFAST element connectors then were employed to represent the bolted joint connection on the Thin-Plate 1 and Thin-Plate 2. The selection of the CFAST element to represent as bolted joint were explained in [30]. The developed FE model is shown in Figure 3. Meanwhile, the input properties values of the bolt used in the FE model are tabulated in Table 2.

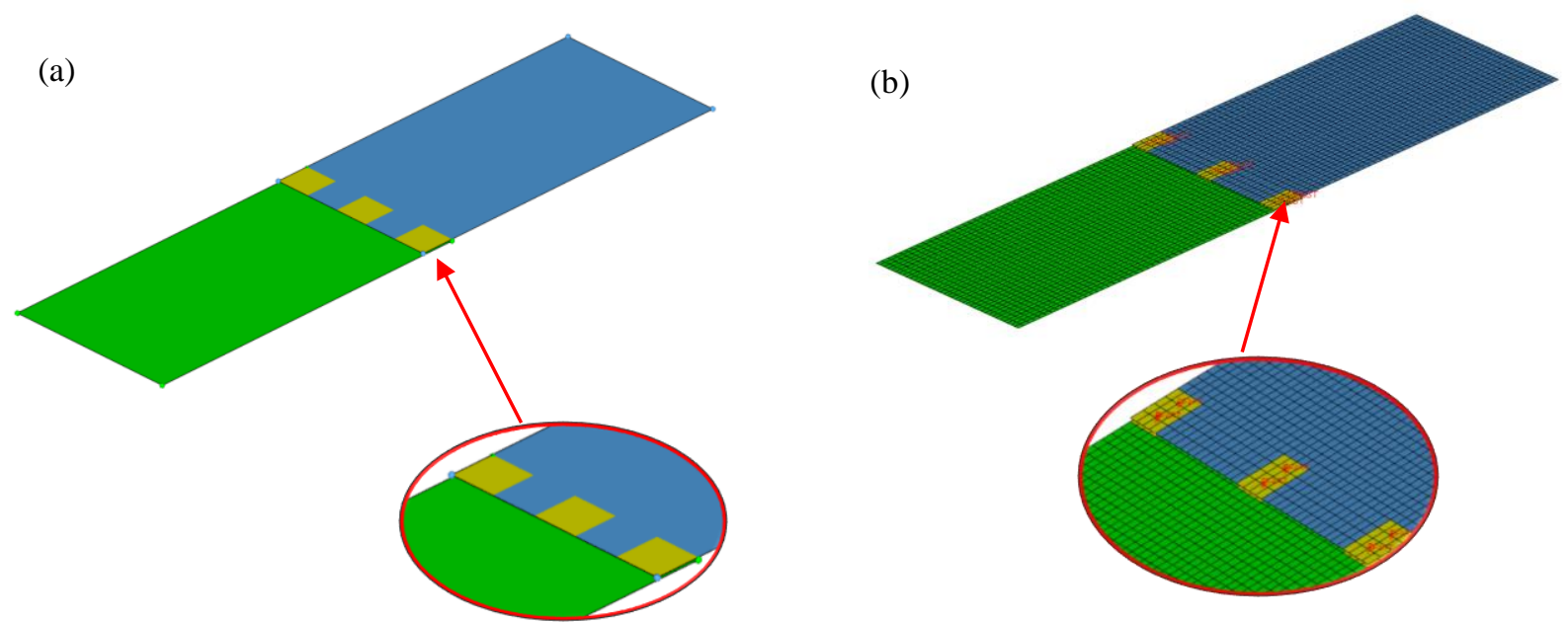

Figure 3. (a) Simplified geometry of the assembled structure and (b) Simplified assembled FE model

Table 2. Values of the bolted joints stiffness

\begin{tabular}{cc}
\hline $\begin{array}{c}\text { Parameters of Bolt Joint } \\
\text { (Translation) }\end{array}$ & $\begin{array}{c}\text { Stiffness Initial Value } \\
(\mathrm{N} / \mathrm{m})\end{array}$ \\
\hline KT1 - X & $1.38 \mathrm{E}+06$ \\
KT2 - Y & $1.02 \mathrm{E}+05$ \\
KT3 - Z & $1.02 \mathrm{E}+05$ \\
\hline
\end{tabular}


In theoritical point of view, the stiffness of the CFAST element is depended on a few parameters that associated with the CFAST fastener property values that can be adjusted such as diameter of bolt $D$, length of the joint $L$, mass of the bolt $M$ and coupling between of 3 translational degree of freedoms (DOFs) in $x, y$ and $z$ directions and 3 rotational along $x, y$ and $z$ axis [30].

The stiffness values of the bolt are described in 6 directions as $K T$ ( 3 Translation in $x, y, z$ direction)

$$
T_{x}=\frac{E A}{L}, \quad \text { and } K T_{y}=K K T_{z=} \frac{1}{C}
$$

and as $K R$ ( 3 rotational along $x, y, z$ axis) of the bolt is specified as,

$$
K R x=\frac{G J}{L}, \quad K R y=K R z=\frac{E I}{L}+\frac{G_{2} A_{s} L}{3}
$$

The fastener flexibility in shear direction based on Douglas formula [30],

$$
c=\frac{1.67}{d_{f} E_{f}}+0.86\left(\frac{1}{t_{1} E_{1}}+\frac{1}{t_{2} E_{2}}\right)
$$

where, A for steel bolts $=1.67$ and B for steel bolts $=0.86, E_{f}$ is Young's modulus of bolt, and $d_{f}$ is diameter of bolts. $E_{1}$ is Young's modulus of first property connected of the bolt and $E_{2}$ is Young's modulus of second property connected of the bolt, $t_{l}$ and $t_{2}$ are thickness of the bolted plates. Meanwhile, the normal mode solution was used to calculated the dynamic behaviour of the components and the bolted joints structure as shown in Figure 3(b). Meanwhile, in the FE modelling, the normal mode solution of the developed model were calculated by solving equation of motion [31]

$$
\mathbf{M} \ddot{x}(t)+\mathbf{C} \dot{x}(t)+\mathbf{K} x(t)=\mathbf{F}(\mathbf{t})
$$

where $\mathbf{M}, \mathbf{C}$, and $\mathbf{K}$ are matrix form of mass, damping and stiffness, while $f(t)$ is the input force and $x(t)$ is the response vector. Considering normal mode solution as free vibration problem and the structures under investigation are undamped system, Eq. (5) can be simplify as

$$
(-\lambda \mathbf{M}+\mathbf{K}) u=0
$$

where $u$ is the $n \times 1$ modal displacement vector, while $\lambda$ is structure responses function of natural frequency.

\section{FE Model Updating}

Commonly, FE model is always differed from their respective physical structure due to invalid assumption used as input of the developed FE model. For instance, the input value of the material properties and boundary conditions are always based on text book values and consequently causing high discrepancies in predicted responses of the developed FE model. Nevertheless, errors of the FE model can be enhanced systematically by comparing the modal properties of the initial FE model and measured structure. Meanwhile, the improvement of an FE model can be divided into two categories, 1) model refinement and 2) model reconciliation [32, 33].

Model refinement is involving the change of the modelling parameters and input properties by introducing the micro scale modelling to the model of the joint. However, to introduce a micro scale modelling to the structure requires a large of modelling affords and computational time. Therefore, it is expensive and impractical for modelling bolted joints with detailed and fine model [27, 33]. Meanwhile, model reconciliation using FE model updating (FEMU) method utilises mathematical means to match experimental result by improving the initial input parameters of the FE model [33, 34].

In the FEMU, the process of correlation is applied iteratively to FE model by utilising the advantages of the experimental results as a benchmark to improve the modal properties by enhancing the initial FE model. At the same time, in the FEMU process, the experimental result is used as a benchmark for improving the initial FE model against the physical structure using objective function as,

$$
J=\sum_{i=1}^{n} W_{i}\left(\frac{\lambda_{i}^{f e}}{\lambda_{i}^{e x p}}-1\right)^{2}
$$

where, $\lambda_{i}^{e x p}$ is the measured frequencies, while $\lambda_{i}^{f e}$ is the ith calculated frequencies from FE analysis.

The iterative model updating scheme is based on the parametrisation of the system matrices and formulated using Eq. (6) as shown in Eq. (8), 


$$
\begin{gathered}
\left(\mathbf{K}-\lambda_{i} \mathbf{M}\right) u_{i}=0 \\
\frac{\partial}{\partial \theta}\left(\mathbf{K}-\lambda_{i} \mathbf{M}\right) u_{i}=0 \\
\left(\mathbf{K}-\lambda_{i} \mathbf{M}\right) \frac{\partial\left(u_{i}\right)}{\partial \theta}+\left(\frac{\partial \mathbf{K}}{\partial \theta}-\frac{\partial \lambda_{i}}{\partial \theta} \mathbf{M}-\lambda_{i} \frac{\partial \mathbf{M}}{\partial \theta}\right) u_{i}=0
\end{gathered}
$$

Multiply by $\boldsymbol{u}_{i}^{T}$

$$
\boldsymbol{u}_{i}^{T}\left(\mathbf{K}-\lambda_{i} \mathbf{M}\right) \frac{\partial\left(u_{i}\right)}{\partial \theta}+\boldsymbol{u}_{i}^{T}\left(\frac{\partial \mathbf{K}}{\partial \theta}-\frac{\partial \lambda_{i}}{\partial \theta} \mathbf{M}-\lambda_{i} \frac{\partial \mathbf{M}}{\partial \theta}\right) u_{i}=0
$$

This leads to the following expression:

$$
\frac{\partial \lambda_{i}}{\partial \theta}=\frac{\boldsymbol{u}_{i}^{T}\left(\frac{\partial \mathbf{K}}{\partial \theta}-\lambda_{i} \frac{\partial \mathbf{M}}{\partial \theta}\right) u_{i}}{\boldsymbol{u}_{i}^{T} \mathbf{M} u_{i}}
$$

Sensitivity matrix at the linearisation point $i$ and the parameter changes calculated from Eq. (12) are added to the initial parameter values at the linearisation point and the objective function are then evaluating and minimising the error using the new design parameters until the objective function achieve the threshold value or converge to an acceptable value.

$$
\mathbf{S}_{i}=\frac{\partial \lambda_{i}}{\partial \theta}=\boldsymbol{u}_{i}^{T}\left(\frac{\partial \mathbf{K}}{\partial \theta}-\lambda_{i} \frac{\partial \mathbf{M}}{\partial \theta}\right) u_{i}
$$

In this study, a validation method was used in quantify the mode shapes from developed FE model and experimental data [35, 36]. Generally, modal assurance criterion (MAC) analysis is calculated by solving Eq.(14) as follow

$$
\mathrm{MAC}=\boldsymbol{\Phi}_{m} \boldsymbol{\Phi}_{a}=\frac{\left|\boldsymbol{\Phi}_{m}^{T} \boldsymbol{\Phi}_{a}\right|^{2}}{\left(\boldsymbol{\Phi}_{a}^{T} \boldsymbol{\Phi}_{a}\right)\left(\boldsymbol{\Phi}_{m}^{T} \boldsymbol{\Phi}_{m}\right)}
$$

where $\boldsymbol{\Phi}_{a}$ and $\boldsymbol{\Phi}_{m}$ represent the mode shapes vector from FE and experimental respectively. The MAC values obtain are vary in scale of 0 (poor correlation) to 1 ( excellent correlation) for representing similarity of mode shapes from different set of data [37].

\section{RESULTS AND DISCUSSION}

Main objective of this research is to propose efficient schemes for accurately predict the bolted joints model via FEMU method. In order to attain the main objective, the dynamic behaviour of the structures under investigation were obtained using EMA and FE method respectively. The relative error obtained from the developed FE models were systematically minimised using FEMU method with EMA of the structures under investigation were used as reference in respectively cases. Initially, the relative error in the FE models of plate components were updated first. These works are crucial in order to focusing modelling error on the bolted joints without conspired by the influence of the structure components.

The calculated and experimental natural frequencies of the plate components are weighed up as tabulated in Table 3 and in Table 4. Only first five modes were utilised in this works. From Table 3 (Column III), the total relative error recorded for natural frequencies of the FE model of Thin-Plate 1 is $15.17 \%$ with MAC values (Column IV) of the first five modes are above 0.7. Meanwhile, in Table 4 (Column III), total relative error recorded for the initial FE model of Thin-Plate 2 is $12.47 \%$ with MAC values (Column IV) of the first five modes are above 0.8. Obviously, the MAC values recorded for the initial FE models shows acceptable similarity between mode shapes of EMA and the initial FE results of Thin-Plate 1 and Thin-Plate 2. However, the results in Column III of Table 3 and Table 4 indicates that the FE model of Thin-Plate 1 and Thin-Plate 2 required to be improved in order to minimise the relative errors originate from the natural frequencies obtained. The difference in the calculated natural frequencies of Thin-Plate 1 and 2 are mainly due to the invalid assumptions made during modelling stages. Generally, the initial assumptions of the initial FE models are based on established data that available in literature [28]. Nevertheless, these assumptions could vary with the physical structure due to the several uncontrolled circumstances such as tolerance in productions, manufacturing defects and temperature influenced [38]. Therefore, systematic method such as FE model updating is required to obtain true values of the assumptions made for improving the prediction of the structure responses. 
Table 3. Comparisons of dynamic behaviour of Thin-Plate 1

\begin{tabular}{|c|c|c|c|c|c|c|c|}
\hline \multirow[b]{2}{*}{ Order } & \multirow{2}{*}{$\begin{array}{c}\text { EMA } \\
\begin{array}{c}\text { Experiment } \\
(\mathrm{Hz})\end{array}\end{array}$} & \multicolumn{3}{|c|}{ Initial FE of Thin-Plate 1} & \multicolumn{3}{|c|}{ Updated FE of Thin-Plate 1} \\
\hline & & $\begin{array}{c}\text { Frequency } \\
(\mathrm{Hz})\end{array}$ & $\begin{array}{l}\text { Error } \\
(\%)\end{array}$ & MAC & $\begin{array}{l}\text { Frequency } \\
(\mathrm{Hz})\end{array}$ & $\begin{array}{l}\text { Error } \\
(\%)\end{array}$ & MAC \\
\hline 1 & 87.45 & 89.14 & 1.93 & 0.88 & 86.51 & 1.07 & 0.90 \\
\hline 2 & 104.82 & 110.04 & 4.98 & 0.83 & 106.78 & 1.87 & 0.83 \\
\hline 3 & 236.97 & 242.28 & 2.24 & 0.85 & 235.12 & 0.78 & 0.87 \\
\hline 4 & 240.21 & 247.74 & 3.13 & 0.79 & 240.44 & 0.10 & 0.82 \\
\hline 5 & 355.34 & 365.6 & 2.89 & 0.83 & 354.82 & 0.15 & 0.87 \\
\hline \multicolumn{2}{|c|}{ Total Error } & & 15.17 & & & 3.97 & \\
\hline
\end{tabular}

Table 4. Comparisons of dynamic behaviour of Thin-Plate 2

\begin{tabular}{|c|c|c|c|c|c|c|c|}
\hline \multirow[b]{2}{*}{ Order } & \multirow{2}{*}{$\begin{array}{c}\text { EMA } \\
\begin{array}{c}\text { Experiment } \\
(\mathrm{Hz})\end{array}\end{array}$} & \multicolumn{3}{|c|}{ Initial FE of Thin-Plate 2} & \multicolumn{3}{|c|}{ Updated FE of Thin-Plate 2} \\
\hline & & $\begin{array}{c}\text { Frequency } \\
(\mathrm{Hz})\end{array}$ & $\begin{array}{c}\text { Error } \\
(\%)\end{array}$ & MAC & $\begin{array}{c}\text { Frequency } \\
(\mathrm{Hz})\end{array}$ & $\begin{array}{c}\text { Error } \\
(\%)\end{array}$ & MAC \\
\hline 1 & 86.76 & 89.14 & 2.74 & 0.87 & 86.96 & 0.23 & 0.90 \\
\hline 2 & 107.21 & 110.04 & 2.64 & 0.83 & 107.36 & 0.14 & 0.83 \\
\hline 3 & 236.58 & 242.28 & 2.41 & 0.86 & 236.40 & 0.08 & 0.87 \\
\hline 4 & 242.46 & 247.74 & 2.18 & 0.80 & 241.71 & 0.31 & 0.82 \\
\hline 5 & 356.69 & 365.6 & 2.50 & 0.85 & 356.70 & 0.00 & 0.87 \\
\hline
\end{tabular}

The identification of the most sensitive parameters of the plate components were calculated using NASTRAN SOL200 solver. There are a few potential parameters that have been listed in the sensitivity analysis as tabulated in Table 1 . Engineering judgement were made for selecting appropriate updating parameters based on sensitivity analysis result. In this process, the structural responses of the Thin-Plate 1 and 2 were more sensitive to the Young's and shear modulus. Consequently, the Young's modulus and shear modulus were used to update the thin-sheet metal components. The results of the updated natural frequencies for the Thin-Plate 1 and 2 were compared with the experimental data in Column $\mathrm{V}$ of Table 3 and Table 4 respectively and together with their updated MAC values. Astonishing improvement can be seen in Column V of Table 3, where the total relative error of the natural frequencies for Thin-Plate 1 is minimised from 15.17 $\%$ to $3.97 \%$ while the total relative error of the natural frequencies for Thin-Plate 2 in Table 4 (Column V) is minimised significantly from $12.47 \%$ to $0.76 \%$. The result proves the capabilities of FE model updating in identifying and correcting invalid initial assumptions made in FE modelling. The results also highlight that, the updated parameters of the Young's and shear modulus are able to improve the first five natural frequencies and MAC values for Thin-Plate 1 (Table 3, Column VI) and Thin-Plate 2 (Table 4, Column VI) with a better correlation of each individual modes. Consequence to the achievement obtained as tabulated in Table 3 and Table 4, the updated FE models of plate components are then were connected by six sets of bolts and nuts using CFAST element connectors to form a bolted joints structure. Therefore, any error emerges from the assembled FE model can be categorise from bolted modelling.

Table 5. Comparisons of natural frequencies (relative error) and mode shapes (MAC) of the assembled structure

\begin{tabular}{|c|c|c|c|c|c|c|c|}
\hline & EMA & \multicolumn{3}{|c|}{ Initial FE of Assembled structure } & \multicolumn{3}{|c|}{ Updated FE of Assembled structure } \\
\hline Order & $\begin{array}{c}\text { Experiment } \\
(\mathrm{Hz})\end{array}$ & $\begin{array}{l}\text { Frequency } \\
\quad(\mathrm{Hz})\end{array}$ & $\begin{array}{c}\text { Error } \\
(\%)\end{array}$ & MAC & $\begin{array}{c}\text { Frequency } \\
(\mathrm{Hz})\end{array}$ & $\begin{array}{c}\text { Error } \\
(\%)\end{array}$ & MAC \\
\hline 1 & 22.43 & 23.99 & 6.95 & 0.85 & 22.57 & 0.62 & 0.90 \\
\hline 2 & 57.25 & 59.36 & 3.69 & 0.81 & 58.75 & 2.62 & 0.83 \\
\hline 3 & 63.87 & 68.34 & 7.00 & 0.83 & 68.29 & 6.92 & 0.87 \\
\hline 4 & 109.02 & 113.07 & 3.71 & 0.82 & 112.3 & 3.01 & 0.82 \\
\hline 5 & 124.56 & 129.14 & 3.68 & 0.80 & 122.72 & 1.48 & 0.87 \\
\hline \multicolumn{2}{|c|}{ Total Error } & & 25.03 & & & 14.65 & \\
\hline
\end{tabular}


As mentioned previously, the CFAST were utilised to establish the bolt joints in the assembled FE. Consequently, assigned input parameters originate from the CFAST element connectors such as translation stiffness in X axis (KT1), Y axis (KT2) and Z axis (KT3) are considered as potential updating parameters. In additions, input parameters for represent mating area in the assembled FE model such as contact stiffness in jointed region between bolts, nuts and thin-sheet metal plates are also considered as potential updating parameters. From sensitivity analysis, it been found that, assembled structure's responses are sensitive to the parameters in CFAST element connectors. The parameters in CFAST element connectors such as translation stiffness in X-direction (KT1), Y-direction (KT2) and Z-direction (KT3) have chosen to be included in the FE model updating scheme as updating parameters. Figure 4 shows parameters changed during updating process.

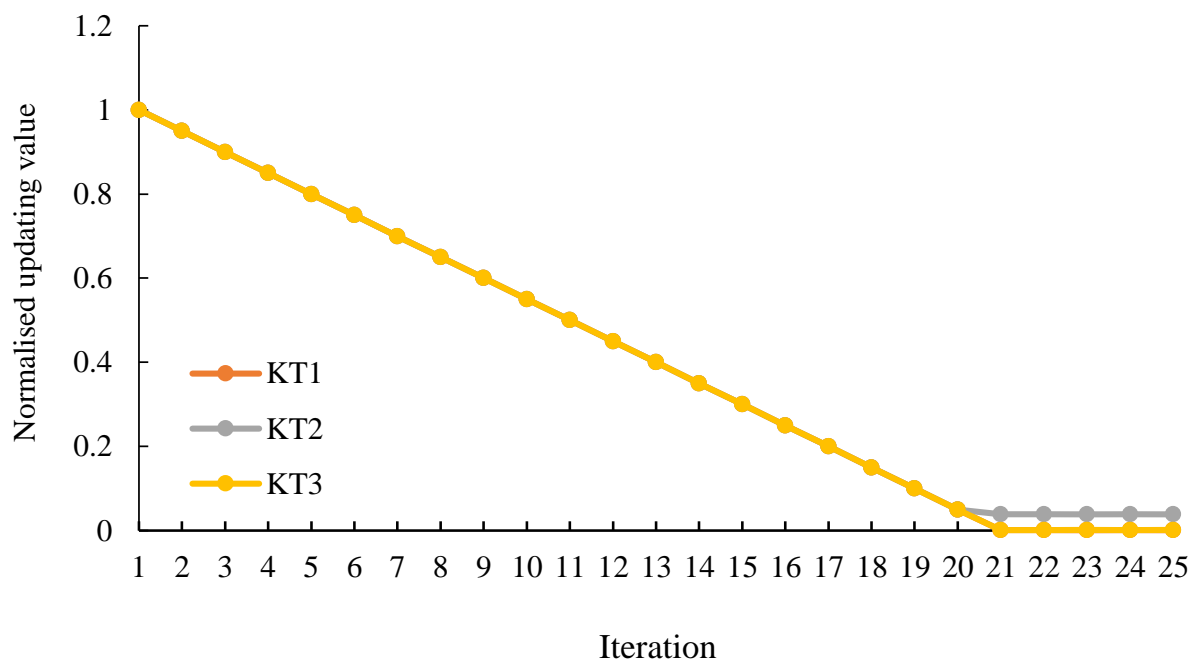

Figure 4. Convergence graph of the updating parameters of the bolted joints stiffness in translations of X (KT1), Y (KT2) and Z (KTZ)

The first five measured natural frequencies and three input parameters in the CFAST element connectors were used in the updating procedure of the initial FE model of the bolted structure. The result shows that discrepancies of the updated are significantly minimised from $25.03 \%$ (Table 5, Column III) to $14.65 \%$ (Table 5, Column VI). Moreover, significant achievement can also be seen in the calculated MAC values of the assembled structure where the updated MAC values recorded are above 0.8. It was discovered that there is substantial reduction in the stiffness values of the X-direction, Ydirection and Z-direction of the bolt joints. These results emphasize that, the FE model updating schemes used in this study managed to identify optimum values of the bolt stiffness in the particular directions and therefore managed to produce an accurate mathematical model of bolt joints.

Table 6. Updated values of the the bolted joints stiffness

\begin{tabular}{cccc}
\hline $\begin{array}{c}\text { Parameters } \\
\text { Stiffness of Bolt }\end{array}$ & $\begin{array}{c}\text { Stiffness Initial } \\
\text { Value }(\mathrm{N} / \mathrm{m})\end{array}$ & $\begin{array}{c}\text { Frictional Value } \\
\text { of the Iteration }\end{array}$ & $\begin{array}{c}\text { Updated Stiffness } \\
\text { Value }(\mathrm{N} / \mathrm{m})\end{array}$ \\
\hline KT1 & $1.38 \mathrm{E}+06$ & $8.24 \mathrm{E}-04$ & $1.14 \mathrm{E}+03$ \\
KT2 & $1.02 \mathrm{E}+05$ & $3.86 \mathrm{E}-02$ & $3.94 \mathrm{E}+03$ \\
KT3 & $1.02 \mathrm{E}+05$ & $1.62 \mathrm{E}-03$ & $1.65 \mathrm{E}+02$ \\
\hline
\end{tabular}

\section{CONCLUSION}

In this paper, the CFAST element were utilised to establish the bolts joint connections in the assembled FE model. The FEMU schemes were successfully implemented and thus enhancing correlation between the FE model and experimental data. Meanwhile rigidities of the bolt in three translation directions $(X, Y$ and $Z)$ can be utilised as simple approach to represent the detailed of the local effects of the bolted joints at the mating areas of the bolts and surface structure. The results show that, relative error originated from updated model is significantly minimised from $25.03 \%$ to $14.65 \%$ and the improvement can be observed for all first five frequencies, together with the MAC values which are above 0.8. Finally, the modelling schemes provided an acceptable understanding in the prediction dynamic behaviour of bolted joint structure. In can be conclude that, the proposed scheme can be used to develop accurate mathematical model consist local effects of bolt joints and the model itself can be utilised in the dynamic analysis of jointed structure with a high level of confident. 


\section{ACKNOWLEDGMENTS}

Special thanks to The Ministry of Higher Education of Malaysia (MOHE) for give generous financial assistance through the FRGS of 600-IRMI/FRGS 5/3 (172/2019).

\section{REFERENCES}

[1] M. A. Yunus, H. Ouyang, M. N. Abdul Rani, and A. A. Misa, "Finite element modelling and updating of bolted joints in a thin sheet metal structure," in 20th International Congress on Sound and Vibration, vol. 2, pp. 1146-1152, 2013.

[2] B. Chang, Y. Shi, and S. Dong, "Studies on a computational model and the stress field characteristics of weld-bonded joints for a car body steel sheet," J. Mater. Process. Technol., vol. 100, no. 1, pp. 171-178, 2000.

[3] R. A. Ibrahim and C. L. Pettit, "Uncertainties and dynamic problems of bolted joints and other fasteners," J. Sound Vib., vol. 279, no. 3-5, pp. 857-936, 2005.

[4] T. Marwala, Finite-element-model updating using computional intelligence techniques: Applications to structural dynamics, 2010 ed. United Kindom, Springer, 2010.

[5] J. E. Mottershead, M. I. Friswell, G. H. T. Ng, and J. a Brandon, "Geometric parameters for finite element model updating of joints and constraints," Mech. Syst. Signal Process., vol. 10, no. 2, pp. 171-182, 1996.

[6] J. W. R. Meggitt and A. T. Moorhouse, "Finite element model updating using in-situ experimental data," J. Sound Vib., vol. 489, pp. 115, 2020.

[7] M. A. Yunus, M. A. S. Aziz Shah, M. N. Abdul Rani, W. I. I. Wan Iskandar Mirza, and S. Kushairi, "Experimental and finite element analysis of laser stitch welded structure,” J. Mech. Eng., vol. 4, no. 3, pp. 155-162, 2017.

[8] S. N. Zahari, A. A. R. Zakaria, M. Sani, and I. Bujang, "A review on model updating of joint structure for dynamic analysis purpose," MATEC Web of Conferences, vol. 74, no. 23, pp. 1-6, 2016.

[9] J. E. Mottershead, C. Mares, M. I. Friswell, and S. James, "Selection and updating of parameters for an aluminium space-frame model," Mech. Syst. Signal Process., vol. 14, no. 6, pp. 923-944, 2000.

[10] J. E. Mottershead and M. I. Friswell, "Model updating in structural dynamics: A survey," Journal of Sound and Vibration, vol. 167, no. 2. pp. 347-375, 1993.

[11] S. Donders, M. Brughmans, L. Hermans, and N. Tzannetakis, "The effect of spot weld failure on dynamic vehicle performance," Sound Vib., vol. 39, no. April, pp. 16-25, 2005.

[12] H. Jalali, H. H. Khodaparast, H. Madinei, and M. I. Friswell, "Stochastic modelling and updating of a joint contact interface," Mech. Syst. Signal Process., vol. 129, pp. 645-658, 2019.

[13] S. Kano, "Microstructure and mechanical property in heat affected zone (HAZ) in F82H jointed with SUS316L by fiber laser welding," Nucl. Mater. Energy, vol. 9, pp. 300-305, 2016.

[14] R. J. Allemang, "The modal assurance criterion - Twenty years of use and abuse," J. Sound Vib., vol. 37, no. 8, pp. 14-21, 2003.

[15] M. A. S. Aziz Shah, M. A. Yunus, M. N. Abdul Rani, N. A. Tormidi, A. A. Mat Isa, and W. I. I. Wan Iskandar Mirza, "Closed mode separation of the symmetrical structure," J. Mech. Eng., vol. 5, no. 3, pp. 88-97, 2018.

[16] D. D. Heiserer, M. Chargin, and D. J. Siela, "High performance, process oriented, weld spot approach," 1st MSC Worldw. Automot. User Conf., pp. 1-14, 1999.

[17] J. Kim, J. C. Yoon, and B. S. Kang, "Finite element analysis and modeling of structure with bolted joints," Appl. Math. Model., vol. 31, no. 5, pp. 895-911, 2007.

[18] Q. Rui, H. Ouyang, and H. Y. Wang, "An efficient statistically equivalent reduced method on stochastic model updating," Appl. Math. Model., vol. 37, no. 8, pp. 6079-6096, 2013.

[19] K. Brown, C. Morrow, S. Durbin, and A. Baca, “Guideline for bolted joint design and analysis: Version 1.0, United States: N. p., 2008.

[20] W. Xiao, K. Mao, B. Li, and S. Lei, "Contact stiffness of bolted joint with different material combination in machine tools," J. Vibroengineering, vol. 16, no. 7, pp. 3281-3293, 2014.

[21] J. Söderberg, “A finite element method for calculating load distributions in bolted joint assemblies,” PhD Thesis, Linkoping University, 2012.

[22] R. Omar, M. N. A. Rani, and M. A. Yunus, "Finite element modelling and updating of a bolted structure using elements representing the stiffness members, bolts and affected areas of the joints," J. Phys. Conf. Ser., vol. 1262, no. 1, 2019.

[23] M. Zhan, Q. Guo, L. Yue, and B. Zhang, "Modeling and stochastic model updating of bolt-jointed structure," Shock Vib., vol. 2018, pp. 1-12, 2018.

[24] F. Kuratani, M. Okuyama, T. Yamauchi, S. Washior, and S. Washio, "Finite element modeling of spot welds for vibration analysis," 5th Asian Conf. Multibody Dyn., Japan, 2010.

[25] S. Sehgal and H. Kumar, "Structural dynamic model updating techniques: A state of the art review," Arch. Comput. Methods Eng., vol. 23, no. 3, pp. 515-533, 2016.

[26] J. E. Mottershead, M. Link, and M. I. Friswell, “The sensitivity method in finite element model updating: A tutorial," Mech. Syst. Signal Process., vol. 25, no. 7, pp. 2275-2296, 2011. 
[27] Y. Yuan and H. Liu, "An iterative method for solving finite element model updating problems," Appl. Math. Model., vol. 35, no. 2, pp. 848-858, 2011.

[28] M. Mahendran, "The modulus of elasticity of steel - Is it $200 \mathrm{GPa}$ ?," Thirteen. Int. Spec. Conf. Cold-Formed Steel Struct. St. Louis, Missouri U.S.A., pp. 641-648, 1996.

[29] X. Liao, J. Zhang, and X. Xu, "Analytical model of bolted joint structure and its nonlinear dynamic characteristics in transient excitation," Shock Vib., vol. 2016, 2016.

[30] MSC.Software Corp., MSC.Nastran 2005, vol. 1. 2005, pp. 1-1008.

[31] M. A. S. A. Shah, M. A. Yunus, A. M. Saman, M. N. A. Rani, A. R. Bahari, and C. Peter, "Finite element model updating of laser stitch welded structure," in IOP Conference Series: Materials Science and Engineering, vol. 506, 2019.

[32] N. M. M. Maia and J. M. M. Silva, Theoretical and Experimental Modal Analysis, 1st editio. Research Studies Press, 1997.

[33] M. Friswell and J. E. Mottershead, Finite Element Model Updating in Structural Dynamics. Netherlands: Springer, 1995.

[34] M. Baruch, "Optimization procedure to correct stiffness and flexibility matrices using vibration tests," AIAA J., vol. 16, no. 11, pp. 1208-1210, 1978.

[35] D. Ewins, Modal Testing: Theory, practice, and application, 2nd ed. United Kindom: Research Studies Press, 2000.

[36] W. Heylen, Modal analysis theory and testing, $1^{\text {st }}$ ed. Belgium: Division of Production Engineering, Machine Design and Automation, Katholieke Universiteit Leuven, 1998.

[37] M. Pastor, M. Binda, and T. Harčarik, “Modal assurance criterion,” Procedia Eng., vol. 48, pp. 543-548, 2012.

[38] G. Steenackers and P. Guillaume, "Finite element model updating taking into account the uncertainty on the modal parameters estimates," J. Sound Vib., vol. 296, no. 4-5, pp. 919-934, 2006. 